\title{
Security Validation Model in Cloud Computing Environment
}

\author{
Shubhashish Goswami, Himanshu Kumar Diwedi
}

\begin{abstract}
Private, Public cloud or a unified cloud system, client's absence of a successful secure computable assessment techniques for handling the security circumstance of its own data foundation overall. This paper gives a quantifiable security assessment framework for various mists that can be gotten to by reliable API. The assessment framework incorporates security checking motor, security recuperation motor, secure computable assessment system, graphical presentation segment \& so on. Secure assessment system makes out of many assessment components comparing various fields, for example, figuring, stockpiling, organize, support, application security and so forth. Every component is doled out 3 tuples on the liabilities, score \& fix strategy. Framework receives "1 vote" system for a field to check its point \& includes synopsis as overall score, \& to make high security. We implement the computable assessment for various cloud environment clients dependent on the G Cloud phase. It displays active security examining for one or different clouds with pictorial diagrams \& clients to adjust arrangement, expand activity \& fix liabilities, in order to increase secureness of cloud assets.
\end{abstract}

Keywords- security, quantifiable evaluation, secure validation,

\section{INTRODUCTION}

Due to advancement of the distributed environment innovation, cloud system has became one normal strategy for making various clients' data framework. AWS, AZURE, Ali baba Company Cloud and so on grow rapidly \& all the high-scale data centers to give cloud system administration [1] general society mists, remote mists, network mists \& crossover mists, all it has countless clients. In any case, as the cloud innovation bring us ease administrations and activity comforts, it likewise caused that the data framework of clients is divided. The cloud clients can't know whether their cloud administrations are sheltered, and whether their information can be securely set in various mists; and can't get a handle on by and large security circumstance and fix security issues with proficient methods [2, 3].

As of now, the host machines, virtual machines,

Revised Manuscript Received on February 15, 2020.

* Correspondence Author

Shubhashish Goswami, Dept. of CSE, Dev Bhoomi Institute of Technology, Dehradun, Uttarakhand, India.

Email: subh.goswami@gmail.com

*Himanshu Kumar Diwedi, Dept. of CSE, Dev Bhoomi Institute of Technology, Dehradun, Uttarakhand, India. Email: himanshudiwedi01@gmail.com

(c) The Authors. Published by Blue Eyes Intelligence Engineering and Sciences Publication (BEIESP). This is an open access article under the CC BY-NC-ND license (http://creativecommons.org/licenses/by-nc-nd/4.0/) secure view, cloud computing

stockpiling gadgets, organize gadgets and so forth inside one cloud system all it has detached secure checking \& fixing implies. For an cloud system, it will be difficulty for the cloud clients, executives \& guests for handling all in all security circumstance of its available or administrable assets. On the off chance that they receive the administrations of various, secure grade will be given progressively confused. Hence, the requirement to upgrade the desire to Cloud Service Providers (CSP) for presenting the progressively verify cloud condition. In any case, confronting diverse CSP \& its very individual private cloud systems, CSP can't likewise set-up an widespread secure board system to fathom the secure implies crosswise over various mists [4]. Cloud clients requires one Global Secure View or User Secure View for the entirety of their data framework maybe made by a few mists, so it is critical to make Local Secure View, Global Secure View \& User Secure View, at that point use those to increase security status. Relational associations accept key employment in this digital world. In Facebook every individual post their distinct opinions. By gathering everyone's information, the assessment of data will be finished and perceive the client interests, for example 2yrs prior an exchange happened on people's Medical consideration and an open meeting among Obama \& opponent in USA within a few hours ten countless number of posts are initiated and its revealed individuals as a rule interest, this kind of online dialogs prompts recognizes the all-inclusive community interest and gives analysis.

We plan a computable secure assessment framework for the distributed environment, as well as secure computable assessment model, graphical showcase segment \& so on [5]. Secure assessment system makes out of many assessment components comparing various fields, for example, processing, stockpiling, organize, upkeep, application security and so on. Every component is doled out 3 tuples on liabilities, score \& fix strategy. The framework receives "1 vote casted a ballot" instrument for a field to check its score and includes the rundown as the all-out score. cloud clients will procure the secure circumstance of their entire data foundation included the asset library through the secure graphical UI \& assess the security level by the grade. Framework can be likewise controlling the clients to fix the shortcomings of clouds. Remaining paper has been composed as pursues: following area presents the interrelated works. Section-3 shows the secure computable assessment framework. Secure assessment streams \& calculations are delineated in the section-4. Model framework \& trials are depicted in section-5. At last, we make the determinations \& represented the future works in the section-6.

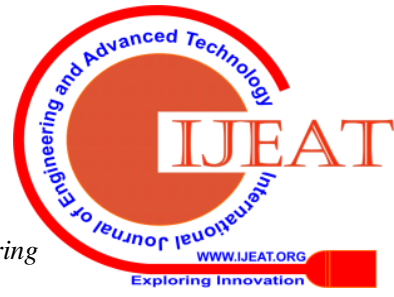




\section{Security Validation Model in Cloud Computing Environment}

\section{LITERATURE WORK}

Distributed environment has been became central innovation \& administration approach in field of I.T. Business method of the cloud made the clients are far away from genuine registering gadgets. Each client's data resources will incorporate it's own PCs, stockpiles, arrange gadgets \& different items that are situated in various mists. Clients have no more productive way for assess the secure in its particular data framework \& need to have confidence on its' cloud specialist co-op. In any case, truth be told, the cloud secure Environment is the unique inquiry, clients are shy of specialized apparatuses to evaluate the cloud status of all its data resources altogether.

Zhange Ming. depicts the incredible necessities in the Cloud Environment, secure key innovation, standard \& guidelines \& so on., and gives a Cloud Environment secure Model [5]. In another survey they called attention to that albeit numerous innovative strategies added to better secure demonstrations in cloud environment, there were still no ideal answers for some difficulties, for example, Service Level Agreement of the security and comprehensive secure instruments will be settled later on [6]. Zunnurhai \& Vrbsk concentrated on the recognizing \& portraying an prime secure assaults on the clouds with objective of the giving hypothetical answers for the singular issues \& coordinating the arrangements [7]. They concentrated on specialized secure issues brought about by utilization of the cloud administrations, particularly cross space secure. Venter \& Whitle inspected distributed system research organized around the mechanical \& administration measurements, including the security equality [8].

There are few literatures about on the most proficient method to give security sees and improved methods for various clients as appeared in the Fig.1., \& how to set-up one computable secure assessment approach for distributed systems stage.

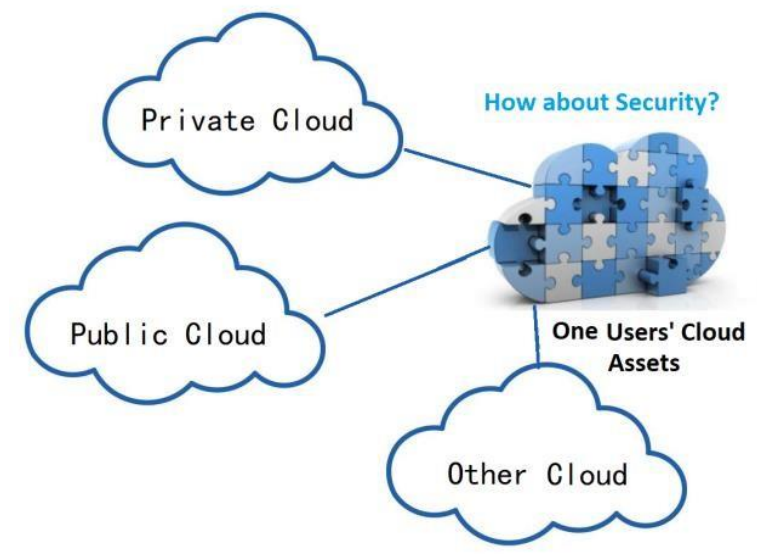

Fig. 1. Active Information Properties of Existing Users

\section{PROPOSED METHODOLOGY}

As appeared in the Fig.2, we make one computable secure assessment framework for solo or multiple cloud stage. Security computable assessment framework incorporates secure representation show segment, lack of security in databases, secure checking motor, recuperation motor, security assessment system, model foundation module and model support module

[9].
The secure computable assessment approach characterizes assortment of the secure things \& computable assessment strategies from different parts of registering secure set, stockpiling secure set, organize secure set, activity and support secure set, application secure set, etc. The segments of assessment frameworks will be sent on the single server or various servers (as individual group) as per the size of checked assets.

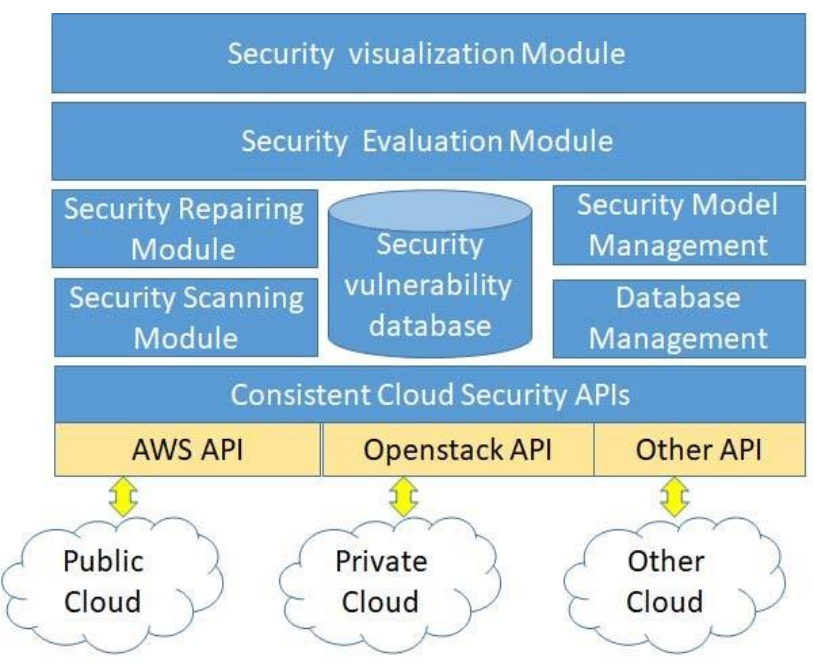

Fig. 2. Proposed Block Diagram

During genuine application, the security examining motor of assessment framework checks the client's security assortment, determined the score of various security things, for example, processing security, stockpiling security, arrange security, upkeep security \& application secure. Filtering will be executed with the sequential \& parallel methods, \& gives out one score for every asset as indicated by the definition of the assessment approach. The computable assessment consequence of general security for each cloud or just a single client is the score as ( 0 - MAX), MAXs is 1,10 , or 100 . At the point when the clients decided to fix secure liabilities, the fix motor was called for the checked liabilities \& fix the liabilities as per the characterized guidelines [10].

\section{PROPOSED SECURITY MODEL}

Center of secure assessment framework is its computable secure assessment approach. It characterizes the secure assessment means \& fix rules. The approach is made by secure master gathering, \& a few things are embraced from the some business or open-source checking motor [11].

\section{Algorithm \& its metrics}

Security Validation Approach is one type of assortment created by the security fields as $\mathrm{P}=\{\mathrm{P} 1, \mathrm{P} 2, \mathrm{P} 3, \mathrm{P} 4, \ldots, \mathrm{PN}\} . \mathrm{Pi}$ is one of the figuring security assortment, stockpiling security assortment, organize security assortment, keep up security assortment, application security assortment and so on [12]. One Pi of P incorporates diverse security checking thing $\mathrm{Pij}$, as physical server OS \& VM os, compartment frameworks, \& other helplessness things. And all the things formed 
Pi. $P_{i}=\left\{P_{i 1}, P_{i 2}, P_{i 3}, P_{i j}, \ldots, P_{i M}\right\}$

Table-I. Secure groups \& objects for the secure measure calculation system.

\begin{tabular}{|c|c|c|c|}
\hline Index & $\begin{array}{r}\text { Collectio } \\
\text { n Name }\end{array}$ & Key Objects & Pointer \\
\hline \multirow{4}{*}{$P$} & \multirow{4}{*}{$\begin{array}{l}\text { Computin } \\
\text { g Security } \\
\text { Collection }\end{array}$} & Host Machine & $P_{11}$ \\
\hline & & Simulated Machine & $P_{12}$ \\
\hline & & Virtual System & $P_{13}$ \\
\hline & & Other things & $P_{14}$ \\
\hline \multirow{5}{*}{$P$} & \multirow{5}{*}{$\begin{array}{c}\text { Storage } \\
\text { Security } \\
\text { Collectio } \\
n\end{array}$} & $\begin{array}{c}\text { Physical systems } \\
\text { storage }\end{array}$ & $P_{21}$ \\
\hline & & Virtual Systems Storage & $P_{22}$ \\
\hline & & Entity Storage & $P_{23}$ \\
\hline & & Chunk Storage & $P_{24}$ \\
\hline & & File System Storage & $P_{25}$ \\
\hline \multirow[b]{3}{*}{$\begin{array}{c}P \\
3\end{array}$} & \multirow{3}{*}{$\begin{array}{l}\text { Network } \\
\text { Securit } \\
\text { y } \\
\text { Collectio } \\
\text { n }\end{array}$} & Network Configuration & $P_{31}$ \\
\hline & & Network Logs & $P_{32}$ \\
\hline & & Network Device & $P_{33}$ \\
\hline \multirow{3}{*}{$\begin{array}{l}P \\
4\end{array}$} & \multirow{3}{*}{$\begin{array}{c}\text { Maintai } \\
\mathrm{n} \\
\text { Securit } \\
\mathrm{y} \\
\text { Collection }\end{array}$} & Maintain Plan & $P_{41}$ \\
\hline & & $\begin{array}{l}\text { Management } \\
\text { Architecture }\end{array}$ & $P_{42}$ \\
\hline & & $\begin{array}{c}\text { Running Safety } \\
\text { Inspection }\end{array}$ & $P_{43}$ \\
\hline \multirow{3}{*}{$\begin{array}{l}P \\
5\end{array}$} & \multirow{3}{*}{$\begin{array}{l}\text { Application } \\
\text { Security } \\
\text { Collectio } \\
\text { n }\end{array}$} & $\begin{array}{l}\text { Application System } \\
\text { Logs }\end{array}$ & $P_{51}$ \\
\hline & & Behavior Audit & $P_{52}$ \\
\hline & & Access Control Strategy & $P_{53}$ \\
\hline
\end{tabular}

Artificial intelligence is comparing to clients' physical machines, VMs and so forth. As appeared in condition (2), Aij is one item expected for verifying the secure status. On off chance that checking, the examining motor will give out one triple $\mathrm{S}=[\mathrm{Sij}$, Lij, Oij].

Sij is the most noteworthy score, $\mathrm{Lij}$ is security helplessness level, and Oij is one connect to the fixed ways. Lij can be leveled confused, with improved methods, it tends to be 0 for top shortcoming and 1 for no security chance.

One Pi relating to one $\mathrm{Si}$, the whole of all out $\mathrm{Si}$ is MAX (as 1 or 100) as condition (3) and condition (4).

$$
\begin{gathered}
S \mathrm{i}=\sum_{i=1}^{M} \mathrm{Sij} \\
M A X=\sum_{i=1}^{N} \mathrm{Si}
\end{gathered}
$$

Si will be constant score as per heaviness of the registering security, stockpiling security or system security to give out one score. At that point to each security checking thing give one score Sij agreeing the significance and weight. Si can likewise be one unique score, and transformed with heaviness of it's checking things.

\section{B. Computable Security Assessment Process}

Characterize the asset assortment that the client can access as UP. UPi is relating to $\mathrm{Pi}$, Pi characterizes the checking things expected to output of UPi.

$U P=\left\{U P_{1}, U P_{2}, U P_{3}, U P_{4}, \ldots, U P_{N}\right\}$

As appeared in Fig.3, the asset perspective on each client is an sub-set of the Resources. Asset perspective on the overseer with most noteworthy benefit is worldwide assets.

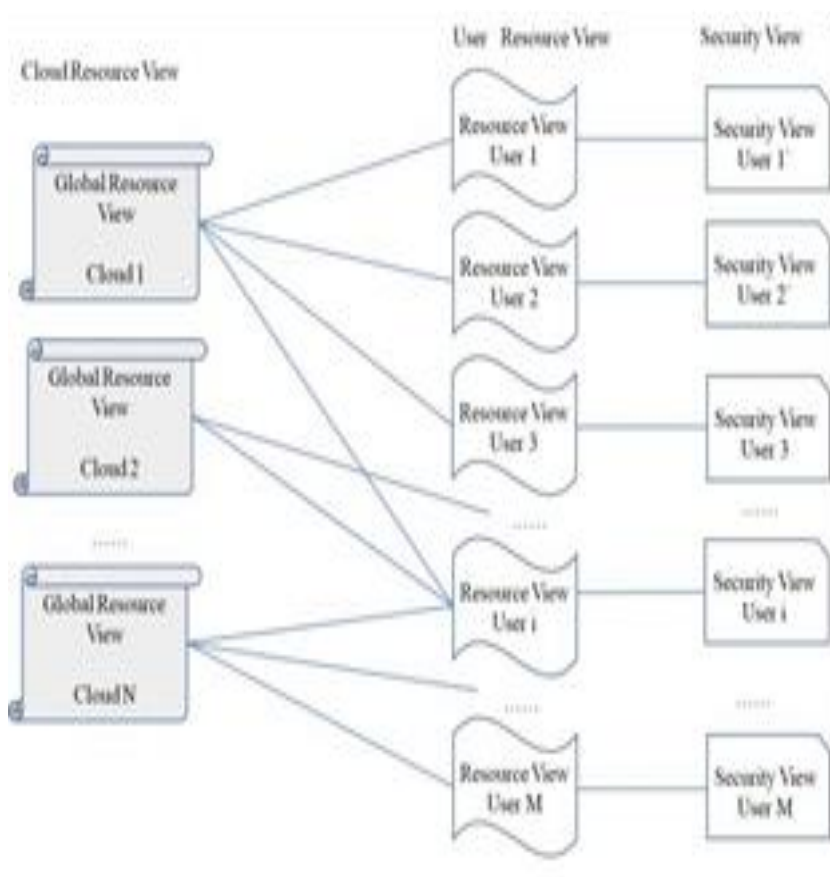

Fig. 3. Flow Diagram of Security Model

Cloud security see is the genuine security score of a wide range of checking things for client's cloud asset see. The chairman can gain the worldwide security see comparing to the all-out cloud. To improve the consideration of one client to the cloud security, we hold this Approach to discourage the score on the off chance that one cloud owning basic defenselessness.

One-Veto Strategy: Consistent to client's secure environment, the aggregate of the strategies worldwide gives computable score. To condense these strategies, the immediate synopsis, normal or one-veto system can be utilized. One-veto methodology implies if the score of one pivotal checking thing is underneath the limit, for example $\mathrm{Lij}$ is 0 , at that point USi is 0 . The security perception module at that point shows the security see with realistically approach, for example the strategies of the secure filtering consequence for one client's cloud assets [13].

\section{Repair Security vulnerability}

At the point when client select to fix the examined openings, the security fix motor will call Oij comparing to Pij. Oij is one connection comparing to the fixing rules to various security opening. The fixing motor will fix the secure gaps sequentially \& parallelly.

As appeared in Fig.4., to one executive or general clients, the security framework calls the fixing motor to fix the security openings, as downloading the patches, changes the arranges, shut the administrations or ports and so forth. The secure fixing motor can fix the gaps quietly or connect with the client through UI. After the fixing motor parts of the bargains, security assessment model at that point gives out one new score, as indicated by the fixed outcomes [14]. 


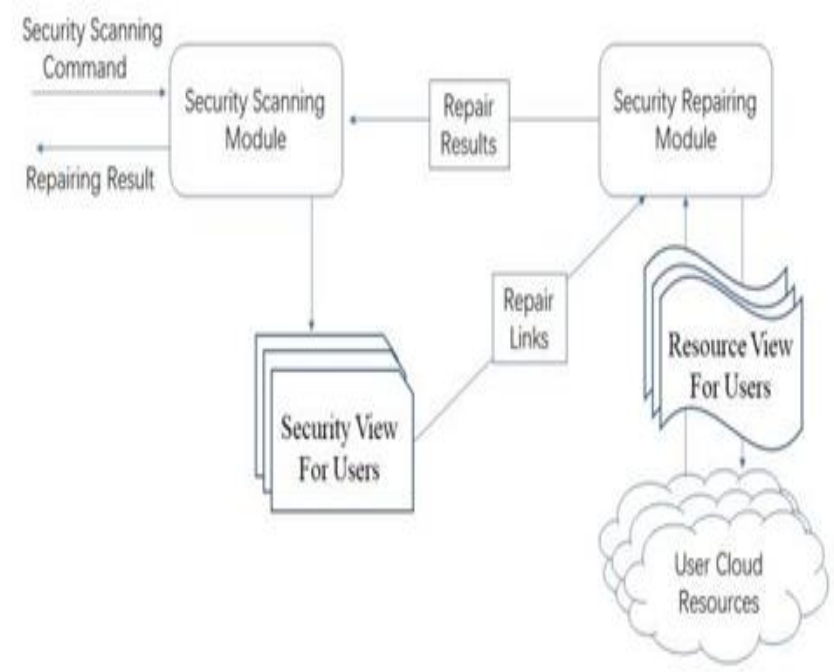

Fig. 4.. Restoring Procedure of Secure Assessment structure

\section{RESULT ANALYSIS}

Usage of our computable secure assessment framework has been done dependent on our G Cloud Platform [15]. Our exploratory stage contains 2 free Clouds. One cloud was set up dependent on G CLOUD OS and one depended on OpenStack. The 2 mists can be checked and communicate with same security API. We utilized 2 gathering of investigations to test what about our assessment framework working for single or twofold cloud stage. The trials were executed with 3000 center figuring asset pool, 200T stockpiling asset Pool and 10GB/S arrange asset pool. The topo chart of the cloud is as appeared in Fig.5. Our exploratory stage contains 2 autonomous Clouds. One cloud is set up dependent on G CLOUD OS and one depends on OpenStack. As appeared in Fig.5, Cloud 1 claims 16 physical machines (all out 512 center) as registering assets and 200TB stockpiling assets. Cloud 2 claims 10 physical machines (all out 320 center) as registering assets and 150TB stockpiling assets. The 2 mists share the system transmission capacity with $40 \mathrm{~Gb} / \mathrm{s}$. The 2 mists can be observed with same security API.

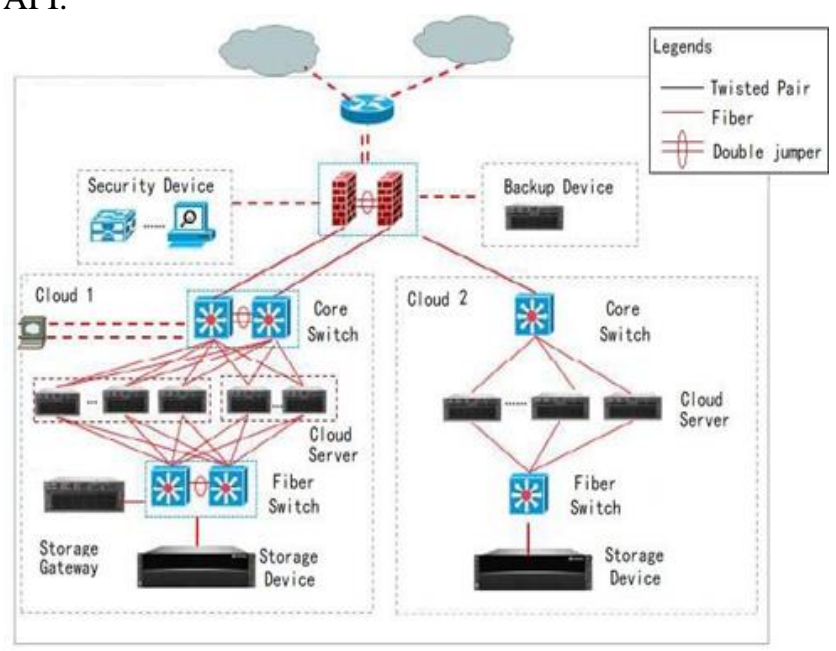

Fig. 5. Experimental Environment for Cloud Security Computable Assessment

We utilized 2 gathering of trials to test what about our assessment framework working. Right off the bat, the examination was executed in cloud 1 to reproduce one private cloud. The running state, asset scale, security score and security pattern were shown on Fig.6. To one cloud stage, the worldwide security checking can be executed cyclicity. As same as this, the security circumstance of 2 cloud can be checked and appeared inside one UI, as the examining module can get to the 2 mists with same API and owing benefits.

The computable assessment means can likewise be utilized to assess the security circumstance of one client. The filtering module will just check the verifying status of the client's assets that were permitted to get to. At that point the security view can be given to show its status. The computable methods can give the directors or clients one instinctive UI to know its security status and guide them to revealing security liabilities. That implies will supplant some non-mechanization security devices to improve the security look after effectiveness.

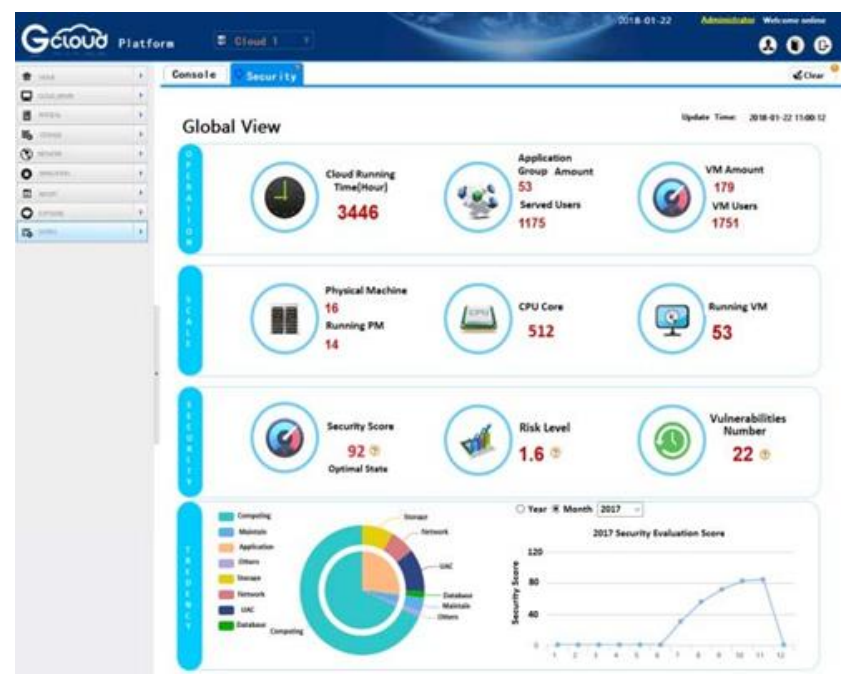

Fig.6. User-Interface for the Secure Computable Assessment

Table II. Time-cost of the secure monitoring with serial/ parallel approach

\begin{tabular}{|c|c|c|c|}
\hline I-D & Scanning Mode & $\begin{array}{c}\text { Serial } \\
\text { Monitoring } \\
\text { Time(s) }\end{array}$ & $\begin{array}{c}\text { Parallel } \\
\text { Monitoring } \\
\text { Time(s) }\end{array}$ \\
\hline 1 & $\begin{array}{c}\text { Global-Scanning } \\
\text { for SingleCloud }\end{array}$ & 3607 & 806 \\
\hline 2 & $\begin{array}{c}\text { Global-Scannin } \\
\text { g for Multiple } \\
\text { Cloud }\end{array}$ & 5700 & 1211 \\
\hline 3 & $\begin{array}{c}\text { User Scanning } \\
\text { in Individual } \\
\text { Cloud }\end{array}$ & 121 & 30 \\
\hline 4 & $\begin{array}{c}\text { User } \\
\text { Scanning in } \\
\text { Multi Cloud }\end{array}$ & 260 & 50 \\
\hline
\end{tabular}

As appeared in Table-2, the secure assessment should be a possible with the sequential and parallel approach. In the event that receiving sequential filtering mode, the verifying checking segment is sent on individual server, \& each figuring asset, stockpiling assets and system assets was examined individually. Now and again the asset scale was large, the worldwide checking time is long to the few hrs.

Published By: 
Therefore, we can embrace the parallel mode to send the security checking module on various servers and separation each cloud into various asset gatherings \& relegated the examining errands to various servers to quicken the checking speed and abbreviate an opportunity to meet client usual meaning. Similarly, the security filtering for the cloud assets of one client in one cloud or multiple clouds will likewise embrace sequential or parallel methods. For the most part, one client's security view can be gained inside 30 s, \& the time can be acknowledged inside a genuine cloud stage for its clients.

\section{CONCLUSION \& FUTURE WORK}

In this research paper, we give a computable secure assessment implies for the individual cloud or multiple cloud environment. computable secure assessment framework incorporates secure examining motor, secure recuperation motor, computable assessment system, graphical presentation segment \& so on. Secure assessment system makes out a lot of assessment components relating various fields, for example, processing, stockpiling, organize, support, application security and so on. Every component is doled out 3 tuples on liabilities, score \& fix strategy. The framework embraces "1 vote voted" instrument for an field to check its score \& includes the outline as overall score.

We actualize the computable assessment framework for various cloud clients on our G-Cloud stage. We implement the computable assessment for various cloud environment clients dependent on the $\mathrm{G}$ Cloud phase. It displays active security examining for one or different clouds with pictorial diagrams \& clients to adjust arrangement, expand activity \& fix liabilities, in order to increase secureness of cloud assets.

\section{REFERENCES}

1. Mohanasundaram, R., A. Jayanthiladevi, and G. Keerthana. "SoftwareDefined Cloud Infrastructure." Handbook of Research on Cloud and Fog Computing Infrastructures for Data Science. IGI Global, 2018. 108-123.

2. Rittinghouse, John W., and James F. Ransome. Cloud computing: implementation, management, and security. CRC press, 2016.

3. Ahmed, Monjur, and Mohammad Ashraf Hossain. "Cloud computing and security issues in the cloud." International Journal of Network Security \& Its Applications 6.1 (2014): 25.

4. $\quad$ Carlin, Sean, and Kevin Curran. "Cloud computing security." (2011)

5. Mxoli, Avuya, Mariana Gerber, and Nicky Mostert-Phipps. "Information security risk measures for Cloud-based Personal Health Records." Information Society (i-Society), 2014 International Conference on. IEEE, 2014

6. Ali, Mazhar, Samee U. Khan, and Athanasios V. Vasilakos. "Security in cloud computing: Opportunities and challenges." Information sciences 305 (2015): 357-383.

7. Rebollo, Oscar, et al. "Empirical evaluation of a cloud computing information security governance framework." Information and Software Technology 58 (2015): 44-57.

8. Chang, Victor, Yen-Hung Kuo, and Muthu Ramachandran. "Cloud computing adoption framework: A security framework for business clouds." Future Generation Computer Systems 57 (2016): 24-41.

9. P. Dileep Kumar Reddy, R. Praveen Sam, C. Shoba Bindu "Optimal Blowfish Algorithm based Technique for Data Security in Cloud"Int J. Business Intelligence and Data Mining, ISSN online 1743-8195, ISSN print 1743-8187, Vol. 11, No. 2, 2016.Pp.171-189.DOI: 10.1504/IJBIDM.2016.10001484. (Inder Science)(UGC Approved). Journal No: 16481

10. P. Dileep Kumar Reddy, R. Praveen Sam, C. Shoba Bindu "Tripartite partite key assignment scheme for security of cloud data classes" Journal of Theoretical and Applied Information Technology, $15^{\text {th }}$ July 2017. Vol.95. No 13, ISSN: 1992-8645, E-ISSN: 1817-3195, Pg.No:3116-3126.(Scopus\& UGC), Journal No: 23566.

11. G. Ramu, P. Dileep Kumar Reddy, Appawala Jayanthi "A Survey of Precision Medicine Strategy Using Cognitive Computing" International Journal of Machine Learning and Computing, Vol. 8, No.
6, December 2018 DOI: 10.18178/IJMLC2018.8.6.741 (Scopus) (UGC Approved) Journal No: 48748, pp 530 to 535.

12. Ummadi Janardhan Reddy, Pandluri Dhanalakshmi, Pallela Dileep Kumar Reddy Image Segmentation Technique Using SVM Classifier for Detection of Medical Disorders Ingénierie des Systèmes d'Information, Vol. 24, No. 2, pp. 173-176, April 2019, https://doi.org/10.18280/isi.240207 (Scopus) ISSN: 1633-1311 (print); 2116-7125 (online) Impact Factor : 0.409

13. Singamaneni Kranthi Kumar, Pallela Dileep Kumar Reddy, Ramesh G, Venkata Rao Maddumala (2019). Image transformation technique using steganography methods using LWT technique. Traitement du Signal, Vol. 36, No. 3, pp. 233-237. June 2019, https://doi.org/10.18280/ts.360305, (WOS, SCI- E) (UGC Care List) ISSN: 0765-0019 (print); 1958-5608 (online) Impact Factor : 0.387

14. J. Somasekar a, , G. Ramesh , Gandikota Ramu, P. Dileep Kumar Reddy, B. Eswara Reddy e, Ching-Hao Lai, "A dataset for automatic contrast enhancement of microscopic malaria infected blood RGB images", Data in brief, Elsevier, https://doi.org/10.1016/j.dib.2019.104643,2352-3409/C 2019. (WOS, E-SCI)

15. Kandala H., Tripathy B.K., Manoj Kumar K. (2018) A Framework to Collect and Visualize User's Browser History for Better User Experience and Personalized Recommendations. In: Satapathy S., Joshi A. (eds) Information and Communication Technology for Intelligent Systems (ICTIS 2017) - Volume 1. ICTIS 2017. Smart Innovation, Systems and Technologies, vol 83. Springer, Cham 